\title{
Analysis of Producer Resilience Strategies to Volatile Cocoa Prices in Cameroon
}

\author{
Kaldjob Mbeh Christian Bernard ${ }^{1,3 *}$, Nso Ngang Andre ${ }^{2}$ and Bamou Tankoua Lydie ${ }^{3}$ \\ ${ }^{1,2}$ Institute of Agricultural Research for Development (IRAD), Yaounde, Cameroon \\ ${ }^{3}$ University of Yaounde II Soa, PO: 14023, Yaounde, Cameroon \\ *Corresponding author: christianbernard.kaldjob@yahoo.fr (ORCID ID: 0000-0003-2461-2135)
}

Received: 01-12-2020 Revised: 02-03-2021 Accepted: 07-03-2021

\begin{abstract}
The fluctuation of cocoa prices in Cameroon is causing important disruptions in the allocation of producers' resources, driving them to adopt resilience strategies. This article provides an analysis of the different strategic options of producer resilience to volatile cocoa prices in Cameroon. Based on revealed preferences and binary logistic regression, it identifies the main strategic resilience options and key factors that explain the choice of these strategies. 390 randomly selected producers in three main divisions of the Center region during the period of September to November 2017, constitute our sample. The results reveal that diversification through fruit trees and input management are the main strategies of producer resilience. Furthermore, factors such as, fruit commercialization, total area, cocoa production, cocoa yield, household size, sex of producer, level of education, Division, are the main factors that explain the adoption resilience strategies. Therefore, the government should provide training to build producers' capacity in risk management and improve the citrus value chain.

Highlights

(0 The cocoa market in Cameroon is very speculative, due to the volatility of its price.

(0 In the context of cocoa prices decrease situation, $69 \%$ and $27 \%$ of producers reduce the production of Orange and Lemon trees respectively.

( Factors such as fruit trees commercialization, division, total area, cocoa production, cocoa yield, gender of producer, Education, are the main determinants of the producer's resilience.
\end{abstract}

Keywords: Cocoa, Diversification, price volatility, Resilience, Strategies, Cameroon

Although considered as a factor of massive deforestation in sub-Saharan Africa, cocoa culture in Cameroon is a different reality. It has been developed in the form of Cocoa Agroforestry Systems (CAS). This type of cocoa production contributes to the diversification of the main speculation in Cameroonian cocoa farms. Indeed, some research shows that the adoption of diversification in CAS, consider as the introduction or development of additional fruit tree species to existing speculation, is one of the producers' strategies to reduce risk and vulnerability to international market instability (Jagoret et al. 2009; Malezieux et Moustier, 2005).

Introduced gradually in Cameroon by missionaries at the beginning of the $20^{\text {th }}$ century, the diversification system consisted first of all in the ostentatious implantation of fruit trees around rural habitats (Dury and Temple 1999). Today, with the various economic shocks suffered by the cocoa sector since the late 1980s, profits from the marketing of fruit trees has sometimes been higher than income from the sale of cocoa. This commercialization, led particularly by women, has given them the

How to cite this article: Bernard, K.M.C., Andre, N.N. and Lydie, B.T. (2021). Analysis of Producer Resilience Strategies to Volatile Cocoa Prices in Cameroon. Economic Affairs, 66(1): 17-26.

Source of Support: None; Conflict of Interest: None

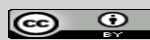


opportunity to participate in the functioning of their households. Diversification in CAS in Cameroon has thus supported the resilience of producers, which is now reflected in their ability to adapt to shocks.

Research on resilience has received a great deal of attention in recent years (Dormady et al. 2018). Jacobi et al. (2019); Prosperi et al. (2016) consider that it is a strategy for mitigating and responding to a risk that predisposes a system to vulnerability. Although there are a myriad of approaches, measuring the resilience of producers to agricultural hazards such as price volatility, there is still a lack of consensus in terms of its definition and its assessment. It is clear that, risks associated with agricultural activities could have more or less negatives consequences on the level of productivity of agricultural holdings. Nevertheless, the concept of resilience in agriculture need to be more assess empiracally in order to improve his comprehension. In the case of CAS, resilience is similar to the ability of cocoa farmers to strengthen their welfare to a sudden modification of price, by modifying their production processes in response to this change (Shi et al. 2018). Overall, several studies reveal the importance of crop diversification as agricultural strategy that improves the resilience of small agricultural systems (Chuku and Okoye 2009; Lin 2011). Therefore, they recommend the adoption of diversified cropping systems to improve farmers' resilience. Chuku and Okoye (2009) conclude that shocks to the agricultural sector in sub-Saharan Africa are precipitated by a system of multiscale stressors. These include price volatility and the effects of globalization. These stressors interact in a complex and disordered way to increase vulnerability and reduce the resilience of producers to risks. From empirical point of view, using a multi-scale approach, Waha et al. (2018) explored the relationship between the diversification potential of African agriculture, its limitations and food security. Roesch-McNally et al. (2018) had examines factors that may influence farmers' decisions to use more diversified crop rotations in the US Corn Belt. Enhancing the resilience of agricultural systems through the adoption of crop diversification could then improve it, although it remains slow (Lin 2011)

In Cameroun, after the withdrawal of the State and the weak accompanying measures due to the liberalization of the sector in the 1990s, Cameroonian cocoa farmers faced increased poverty, with a greater impact in traditional production areas. As a result, they have used lower-cost production systems to respond to market risks. Indeed, the cocoa market in Cameroon is very speculative, due to the volatility of its price (Fig. 1).

Faced with this situation, the producer is disadvantaged because of the informational asymmetry on price formation mechanisms. Despite the existence of price variations that cause technical disruptions in the allocation of their resources, they are also affected by intermediaries who sell them only a fraction of the market price by imposing loans at usurious rates. Under the assumption that producers adapt to changes in the price of cocoa, Dedieu et al. (2006) have shown that to compensate for the loss of income in this case, producers diversify their production by introducing fruit species into CAS. Therefore, according to the

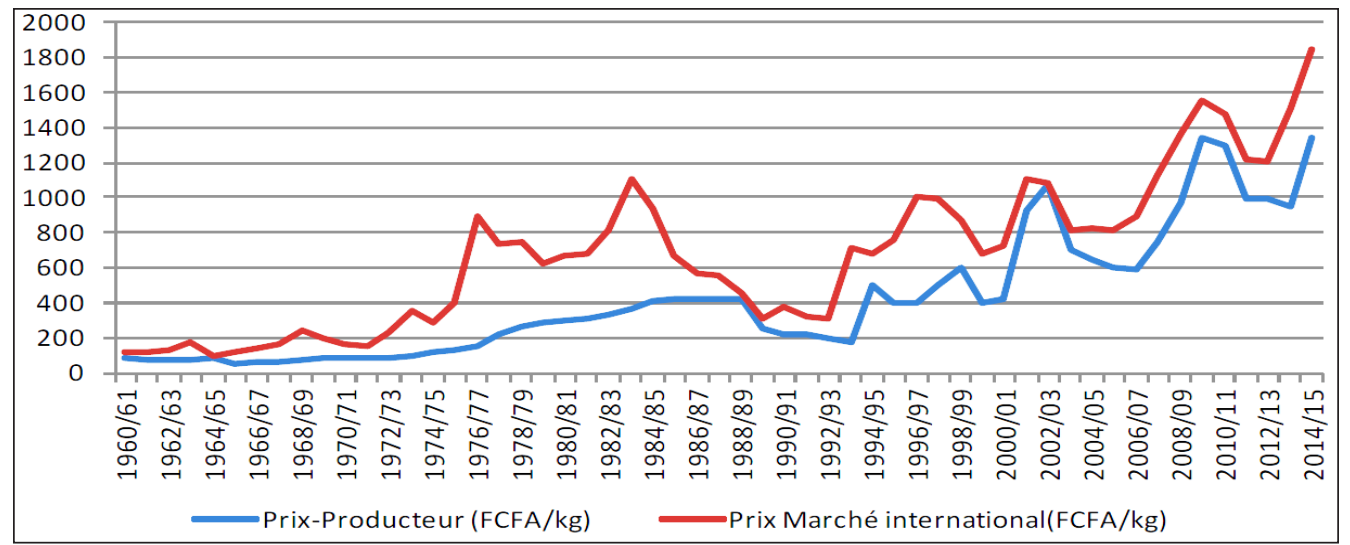

Source: Adapted from Kamdem (2019).

Fig. 1: Evolution of cocoa price in Cameroon and in the international market 
literature, we propose in this article to analyses the cocoa producers 'resilience through socioeconomic and agronomic strategies and identify main determinants of their resilience in a context of price volatility of merchant cocoa.

\section{MATERIALS AND METHODS}

\section{Study area}

The study is conducted in the central region of Cameroon (Fig. 2). With an area of $68,953 \mathrm{~km}^{2}$, its choice is justified by the fact that this is one of the main cocoa production basins in Cameroon. It is characterized by an equatorial climate favorable to the development of cocoaculture. Cocoa is one of the main sources of income for the population, nearly $60 \%$ of producers use it in polyculture and the rest in monoculture.

Market gardening and food crops also contribute significantly to the household economy. Livestock farming is almost non-existent, but it is compensated for by a highly developed poultry farming system. Industrialization of the region remains timid, still dominated by sawmills and wood processing units. In general, people are engaged in petty trade, food agriculture, and hunting.

\section{Data collection}

This study was carried out in three divisions in the central region of Cameroon (Lekie, Mbam and Kim and Mbam and Inoubou), where a sample of 390 producers was selected in a random and reasoned stratified manner. It consists of understanding the difficulties and strategies of cocoa producers in the context of price volatility. Essentially, primary data of socio-demographic characteristics (age, gender, Education, group membership...), agricultural characteristics (area, total production, yield...) and producer resilience strategies as dependent variable, were collected through a survey framework during the period of September to November 2017 (Table 1).

\section{Estimation method}

\section{Identification of cocoa farmer behavior: the methods of declared preferences}

In order to determine the choices of producers' strategies in the face of price variation, a simple self-assessment of their willingness to take risks was conducted. It consists in categorizing producers in the area into two groups divided into two modalities: 0 and 1, with 0 being the category of producers willing to make no changes in their cocoa farms and 1 being the category of producers who decide to modify their production process due to price variations. The next step is to determine the main changes made by this last category of producers.

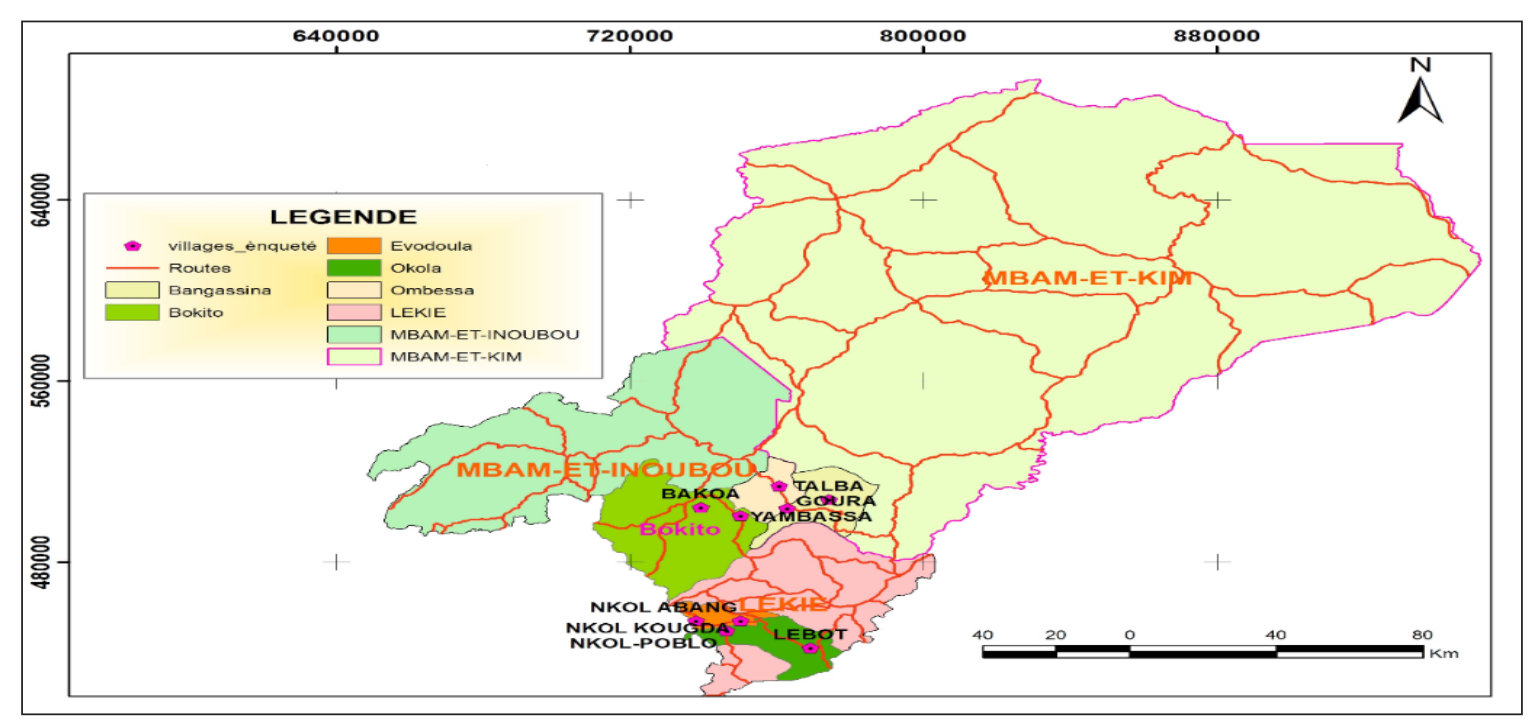

Source: Authors.

Fig. 2: Study area 


\section{Identification of main resilience determinants: a logistic regression approach}

The resilience of a cocoa producer to price volatility, which is modelised as the choice between two alternatives: to modify or to unchange an input, can be represented by a latent variable $R^{*}$ such as:

$$
R^{*}=X_{i} \beta+\varepsilon_{i} i=1, \ldots \ldots, n
$$

$X_{i}=$ a vector of explanatory variables; $\beta$ a vector of parameters.

The event we are interested in is the choice of a strategy and its effect on the level of utility of producers. The producer has to choose between "change" and "unchanged" input. Each of these choices provides some utility to the producer. $R^{*}$ is the difference in utility between resilience strategy choices such as:

$$
R^{*}=U_{i 1}-U_{i 0}
$$

$U_{i 1}=$ the utility of the producer $i$ if he chooses to modify his inputs; $U_{i 0}=$ the utility of the producer $i$ if he chooses to unchanged them.

Under the assumption of the producer's rationality, and that the utility difference is positive, then he will change his inputs. If it's negative, he will not.

It is therefore possible to observe the producer $i$ behavior and represent the variable and $R_{i}$ which takes the values of 1 if he modify and 0 if not. The relationship between the latent variable $R^{*}$ and the one observed $R_{i}$ is as follows:

$$
R_{i}=f\left(R_{i}^{*}\right)=\left\{\begin{array}{l}
1 \text { if } R^{*} \geq 0 \\
0 \text { if } R^{*} \leq 0
\end{array}\right.
$$

The probability of modifying his inputs will therefore be written as follows:

$$
\begin{aligned}
& P\left(R_{i}=\frac{1}{X_{i}}\right)=P\left[f\left(R_{i}^{*}\right)=\frac{1}{X_{i}}\right] \\
& =P\left[R_{i}^{*}=X_{i} \beta+\varepsilon_{i}\right] \geq 0 \\
& =F\left(X_{i} \beta\right)
\end{aligned}
$$

Where $F($.$) refers to the distribution function.$

To analyze the resilience of cocoa farmers, we use a Logistic model because of its simplicity in estimating resilience variables. The $F($.$) fonction is$ a Logistic function such as:

$$
\begin{aligned}
& F(w)=\frac{e^{w}}{1+e^{w}} \\
& =\frac{1}{1+e^{-\omega}} \quad \forall \omega \in \mathfrak{R}
\end{aligned}
$$

Then,

$$
F\left(X_{i} \beta\right)=\frac{e^{X_{i} \beta}}{1+e^{-X_{i} \beta}}
$$

\section{RESULTS AND DISCUSSION}

The presentation of different cocoa farmers' resilience strategies relating to association with fruit trees and the management of inputs in the context of price volatility. It requires first of all a statistical description and interpretation of the results of the socio-economic parameters.

\section{Description of socio-economic variables}

The statistical distribution of socio-economic variables shows a disparity between the three areas (Table 2). Indeed, the average age in the three areas is 53, 50 and 48 years respectively. The locality of Obala among the three is the one that has a maximum number of individuals in a single family with 27 individuals. In addition, in this locality, cocoa farmers have more experience with almost 70 years at least for the most experienced.

The gender distribution remains unequal where only $20 \%$ of cocoa farmers in Obala and Mbam and Kim are women (Fig. 3).

This further justifies the place of men on cocoa farming in this region. In term of education, 38\% of producers in Mbam and Inoubou have reached at least a secondary level, were only $7.5 \%$ in Mbam and Kim had access to higher education. But the majority (70\%), have never received any education. This reveals that most of producer here is undereducated. Membership of a farmers' organization (PO) remains important for the producer's access to information, training and agricultural retraining. Thus, with $79 \%$ belonging to a rural group, Obala has the largest number of members among the three localities.

The results related to agricultural characteristics 
Table 2: Descriptive statistics of socioedemographics variables

\begin{tabular}{lllllllllllll}
\hline Localities & Obala & \multicolumn{1}{c}{ Mbam and Inoubou } & \multicolumn{6}{c}{ Mbam and Kim } \\
\hline Variable & Mean & Stdr. & Min. & Max & Mean & Stdr. & Min & Max & Mean & Ecart-ty & Min & Max \\
\hline Age & 53 & 13,4 & 21 & 87 & 50 & 11,3 & 24 & 75 & 48 & 12,7 & 23 & 82 \\
Household & 7,9 & 4,9 & 1 & 27 & 9 & 4,3 & 1 & 20 & 10,6 & 4,2 & 3 & 27 \\
Experience & 15,2 & 15,5 & 1 & 70 & 15,2 & 9,3 & 3 & 42 & 15,5 & 10,3 & 2 & 48 \\
\hline
\end{tabular}

Source: Author's construction.

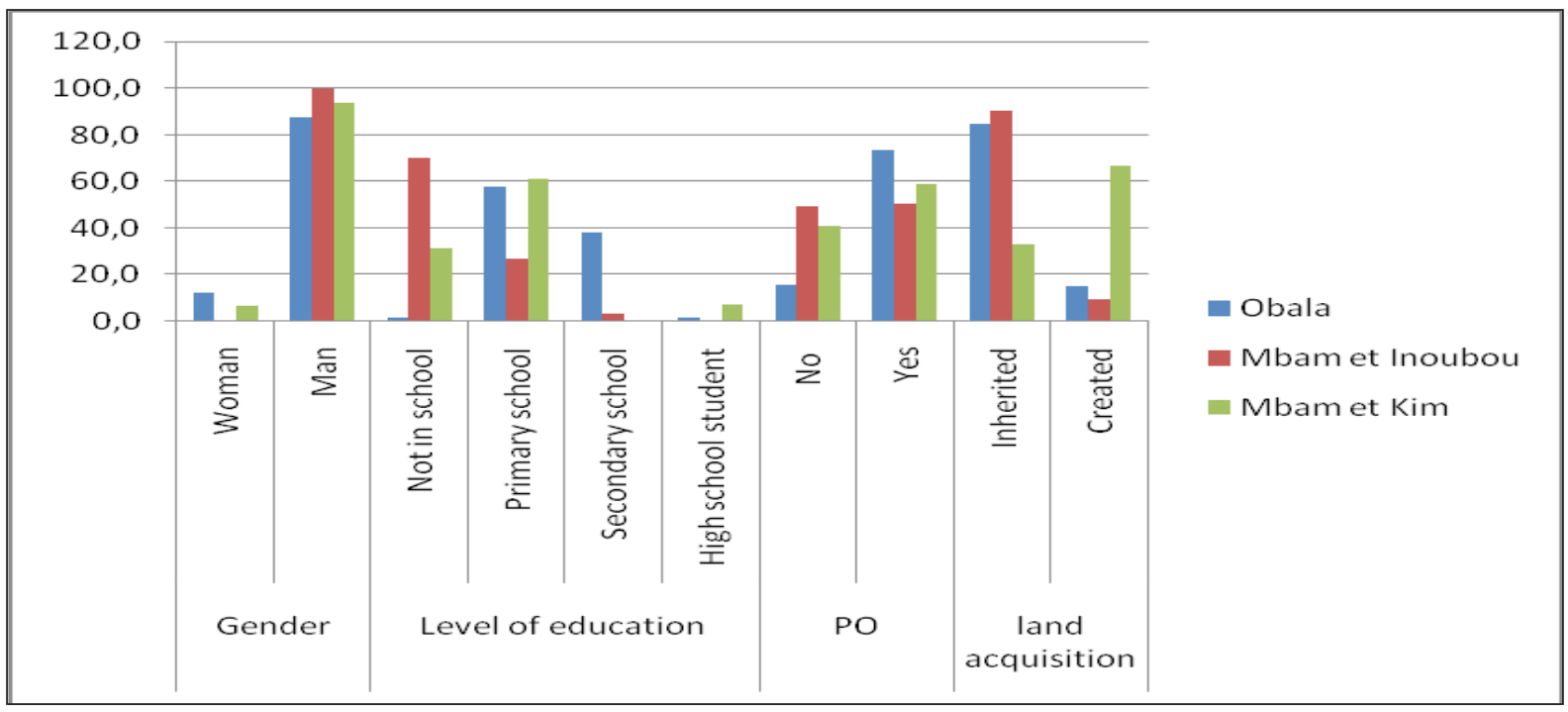

Source: Author's construction.

Fig. 3: Distribution of socioedemographics variables

illustrate that the average yields are not sufficiently high for the three localities, nevertheless, the most interesting yield per hectare is in Mbam and Kim with approximately $700 \mathrm{~kg} / \mathrm{ha}$ on average. This yield is certainly justified by the fact that it is the locality where the plots areas are the largest, with 6.3 ha for the largest, it also remains the locality where producers create more plots during an agricultural season with $66 \%$ of plots created.

\section{Strategies of fruit trees management in the context of price fluctuations}

Faced with the variation in cocoa prices, two major producer groups stand out in the choice of their strategies (Fig. 4). Each group opts for a different managerial strategy of fruit tree association and input management, depending on its perception of the economic importance and level of risk of each speculation.

For the management of fruit trees, when prices decrease, $69 \%$ and $27 \%$ of producers modify their strategies by reducing the production of Orange and Lemon trees respectively. This is because these citrus fruits constitute production risks due to fruit flies, aphids, mealybugs, psylla and other disease such as phaeoramulariasis (Ndo 2011). On the other hand, $75 \%$ and $58 \%$ of producers are increasing their production of Safou and mandarins because these trees produce an economic profitability that allows them to generate savings. In addition, both categories of producers maintain their Djansang production standard unchanged because this Non-Timber Forest Product has a high economic profitability.

\section{Inputs and Associated trees Management strategies to cope with the fluctuation in the price cocoa}

Results of table 1 show that, in a situation of prices increase, all the producers maintain their simple treatment unchanged, and $28.71 \%$ modify it. On the other hand, in a situation of prices decreasing, $71.28 \%$ decided to modify the quantities of inputs in the plots to certainly maintain the same level of productivity. This is explained by the fact that each 
Table 3: Distribution of agricultural variables

\begin{tabular}{lllllllllllll}
\hline Localities & Obala & \multicolumn{1}{c}{} & \multicolumn{4}{c}{ Mbam and Inoubou } & \multicolumn{7}{c}{ Mbam and Kim } \\
\hline Variable & Mean & Stdr & Min & Max & Mean & Stdr & Min & Max & Mean & Stdr & Min & Max \\
\hline Area & 2,3 & 1,7 & 0,3 & 11,5 & 2,3 & 1,3 & 0,5 & 7 & 6,7 & 6,3 & 1 & 42 \\
Production & 1038,2 & 783,5 & 100 & 5000 & 770,8 & 535,4 & 80 & 3300 & 4152,8 & 4767,6 & 500 & 27840 \\
Yield & 532,8 & 337,7 & 125 & 1600 & 347,1 & 165,1 & 120 & 860 & 686,1 & 393,9 & 128 & 1500 \\
\hline
\end{tabular}

Source : Author's Construction.

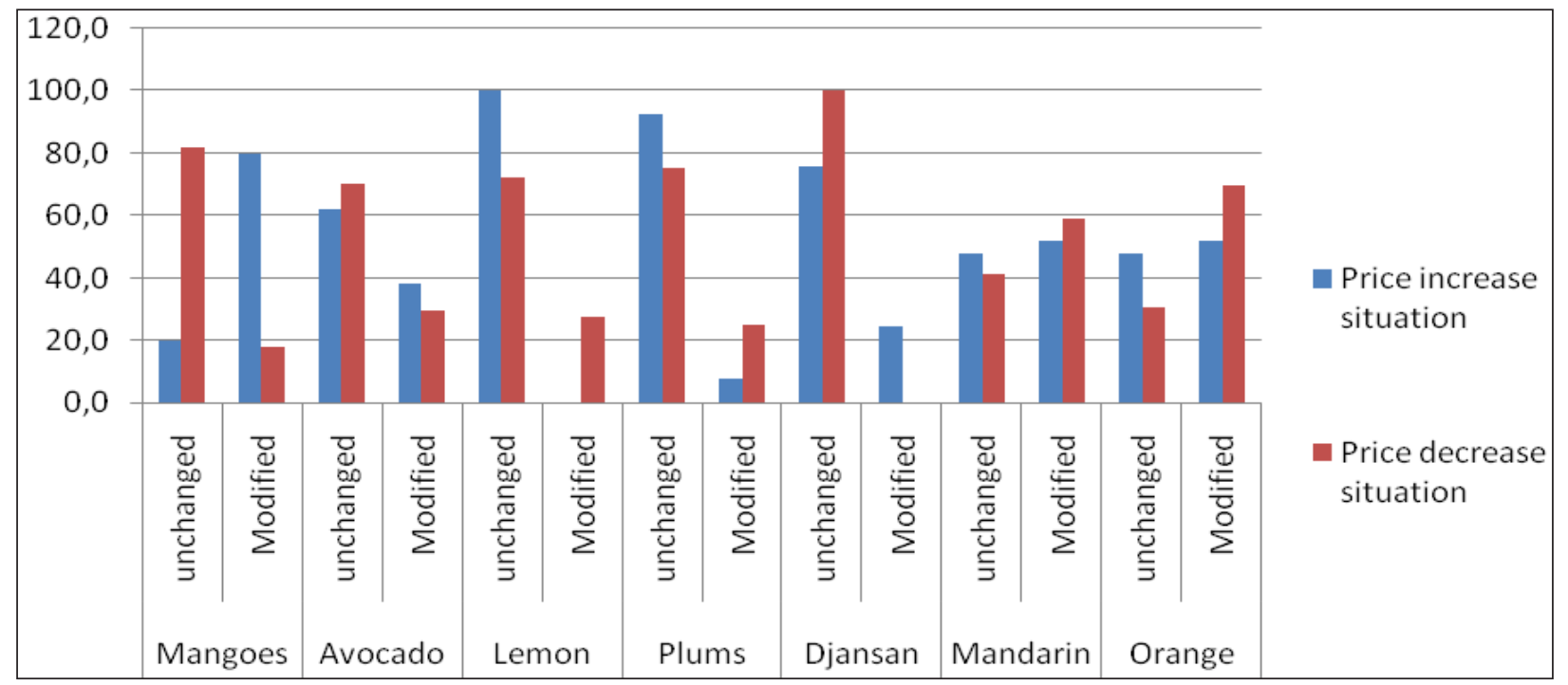

Source: Authors using survey data

Fig. 4: Fruit tree management strategies in response to cocoa price fluctuations

producer's objective is to increase the productivity of the plots, ultimately increasing the volume of his sales.

In addition, for mixed treatment and maintenance, it is also observed that $37.17 \%$ keep it unchanged while $61.53 \%$ modify it, which is also in line with the economic objectives of cocoa farmers in the area. According to the results in (Table 5), when the market price of cocoa increase, producers as a whole tends to neglect the associated trees. This wasteful situation is characterized in CAS by the presence of a large number of fruits that rot on the ground during the harvest period.

However, in a situation of price decrease, the same fruit trees have a strong economic interest for producers who combine the sale of cocoa with the marketing of those fruits in order to diversify and increase their income. It can therefore be seen that diversification trough fruit trees, as a resilience strategy helps to maintain the income level of producers constant in the context of price volatility.

\section{Determinants of resilience strategies to cocoa price volatility}

Exploiting a Logit regression model we have identified main determinants that explain the choice of resilience strategies by cocoa producers (Table 6).

Thus, in the context of price volatility, the results reveal that, factors such as fruit trees commercialization, division, total area, cocoa production, cocoa yield, gender of producer, Education, are globally the main determinants of that explain the resilience of producers.

Production, total area and yield appear to be significant determinants in the choice of resilience strategies. However, yield seems to be negatively correlated with price variations. This is explained on the one hand by the fact that production and yield are not always a function of the current price trend. On the other hand, it reveals that the factors of production in this case (land) are not allocated in an optimal way by producers. Among other things, the drop in the price of cocoa is leading to a certain 
Table 4: Management of Inputs strategies and the fluctuation in the price cocoa

\begin{tabular}{llll}
\hline Treatment & Strategies & Price increase & Price decrease \\
\hline \multirow{2}{*}{ Simple } & Unchanged & 100,00 & 28,71 \\
& Modified & 0 & 71,28 \\
\multirow{2}{*}{ Mixed } & Unchanged & 62,82 & 61,53 \\
& Modified & 37,17 & 38,46 \\
\multirow{2}{*}{ Maintenance } & Unchanged & 37,94 & 36,41 \\
& Modified & 62,05 & 63,59 \\
\hline
\end{tabular}

Sources: Authors using survey data.

Table 5: Strategies of associated trees by producers changing their interest in response to fluctuations in cocoa

\begin{tabular}{llll}
\hline Associated trees & Strategies & Price increase (\%) & Price decrease (\%) \\
\hline Mangoes & Little interest shown & 100 & 100 \\
& Strong interest shown & 0 & 0 \\
Avocado & Little interest shown & 100 & 100 \\
& Strong interest shown & 0 & 0 \\
Lemon & Little interest shown & 100 & 0 \\
& Strong interest shown & 0 & 700 \\
Plums & Little interest shown & 100 & 92,78 \\
& Strong interest shown & 0 & $\mathrm{n} / \mathrm{a}$ \\
Djansan & Little interest shown & 100 & $\mathrm{n} / \mathrm{a}$ \\
\multirow{3}{*}{ Mandarin } & Strong interest shown & 0 & 0 \\
& Little interest shown & 100 & 100 \\
Orange & Strong interest shown & 0 & 0 \\
& Little interest shown & 100 & 100 \\
\hline
\end{tabular}

Sources: Authors using survey data.

Table 6: Determinants of chosen resilience strategies in case of cocoa price increase

\begin{tabular}{|c|c|c|c|c|}
\hline \multicolumn{5}{|l|}{ Logit Regression } \\
\hline \multicolumn{5}{|l|}{ Number of obs $=389$} \\
\hline \multicolumn{5}{|l|}{ LR $\operatorname{chi}^{2}(13)=307.39$} \\
\hline \multicolumn{5}{|l|}{ prob $>$ chi $^{2}=0.000$} \\
\hline \multicolumn{5}{|l|}{ Pseudo $\mathrm{R}^{2}=0.570$} \\
\hline Resilience & Coef. & Std.Err & $\mathrm{z}$ & $P>|z|$ \\
\hline Division & 0.220 & 0.358 & 0.62 & $0.005^{* * *}$ \\
\hline Age & -0.347 & 0.688 & -0.50 & $0.061^{* *}$ \\
\hline Gender & 0.004 & 0.017 & 0.28 & 0.783 \\
\hline Educ & -0.125 & 0.278 & -0.45 & $0.065^{* *}$ \\
\hline Household & -0.056 & 0.038 & -1.46 & $0.104^{*}$ \\
\hline Experience & -0.023 & 0.018 & -1.28 & 0.201 \\
\hline op & 0.005 & 0.389 & 0.01 & 0.988 \\
\hline Landacquisition & 0.143 & 0.466 & 0.31 & 0.759 \\
\hline Fruit commercialisation & 0.346 & 0.469 & 0.74 & $0.000^{* * *}$ \\
\hline Plots & -0.229 & 0.280 & -0.82 & 0.413 \\
\hline Total area & 1.913 & 0.5221 & 3.66 & $0.000^{* * *}$ \\
\hline Production & -0.003 & 0.000 & -3.72 & $0.000^{* * *}$ \\
\hline Yield & -0.002 & 0.001 & -1.60 & $0.000^{* * *}$ \\
\hline _cons & 1.696 & 1.908 & 0.89 & 0.374 \\
\hline
\end{tabular}

Source: Authors using survey data. 
disinterest in production by producers in this area. Finally, this result also characterizes a certain lack of knowledge of the actual areas exploited in the CAS in the central region. Although the parcels here represent good markers of land ownership by producers.

In a situation of increase in cocoa prices, the characteristics of the Lekie division are also one of the significant factors in the resilience of producers. In fact, the locality of Obala represents one of the oldest production basins in the country and the producers are the most efficient. Despite the small plots they have, they manage to exploit them rationally. This production basin is the closest to the major markets in the urban centre, where producers, buyers and sellers commercialize their seasonal products. The combination of citrus fruits is also an explanatory factor in the choice of resilience strategies as it helps to mitigate shocks due to changes in cocoa prices. It also supports producers by providing them with additional income after the marketing of the various citrus fruits and other associated trees. Finally, socio-economic parameters such as gender, household size and producer education level are among other variables that explain the choice of producers' resilience strategies.

This study illustrated that in terms of resilience strategies, the majority of producers, in addition to cocoa, integrate other fruit trees such as citrus fruits, mangoes, plums and avocados into CAS. This conclusion is confirm by Amougou et al. (2013) who also conclude that fruits trees in cocoaculture plays an important role in economic development in Cameroon. As part of diversification, the results on the strategies adopted by farmers to deal with price volatility help to support the producer's resilience on their farm. Factors such as yield, total area, production level, were also identified as determinants of resilience. These results are confirmed by Degrande et al. (2006), who identified the key factors in cocoa resilience strategies. They consider market access, land use and access to forest resources to be important factors. This study showed that producers depend on the marketing of cocoa and associated trees according to price trends. Indeed, the variation in the price of cocoa affects household income. However, in this study, cocoa farmers' families market the associated crops as alternative sources of income. Thus, due to the instability of these incomes during the year, it is useful for the resilience of these farming families to have secondary sources of income during the months without cocoa sales. Similarly, the fluctuation in cocoa income at the household level reinforces the idea that non-timber forest products and other edible products can also provide additional income to conventional perennial crops and thus contribute to their resilience. Those results confirm the conclusions of Sonwa et al. (2014) studies.

The resilience of cocoa farmers may be better if farms were not confronted with high parasitic pressures, mainly diseases and insect pests. The research of Ndoumbe-Nkeng et al. (2004) confirm this result, as he conclude that the losses due to diseases can reach 70 to $100 \%$ in the absence of phyto-sanitary treatment. In order to reduce pest pressure to acceptable levels, farmers commonly use pesticides (Tadu et al. 2014; Tijani 2006) dangers associated with their use and established regulatory incentive (if any. According to Mahob et al. (2014) studies Improving phytosanitary control and raising producers' awareness of the use of these pesticides could therefore make a significant contribution to the economic resilience of cocoa farming. The main maintenance requirements of a cocoa farm are shading, weeding. For Jagoret et al. (2011), 91\% of cocoa plantations are weeded two and three times a year. This result confirms the result obtained according to which $62.05 \%$ of producers increase the level of maintenance in cocoa farms when prices are on the rise.

\section{CONCLUSION}

Twenty-five years after the liberalization of the cocoa sector in Cameroon, producers continue to suffer the effects of multiple exogenous shocks, which are characterized in particular by price instability on the markets. This paper, by presenting agricultural diversification as the main resilience strategy, illustrated one of the solutions among the myriad of agricultural risk management options available to producers. Thus, diversification as a strategy of resilience is in itself an interesting form of endogenous response, although the valuation of the various fruit trees (lemon, orange, mango, avocado, plum...) and the management of phytosanitary 
treatments (simple and mixed) in the study area still depend strongly on the level of cocoa price of the period. Therefore, government trough the ministry of trade should provide and disseminate a good quality of information on the cocoa market dynamic and also implement training for cocoa producers to enhance their capacity building on risk management practices.

\section{ACKNOWLEDGEMENTS}

The authors are grateful to all the producers of la Lekié, Mbam and Kim, Mbam and Inoubou divisions for providing all information in order to facilitate the production of this research.

\section{REFERENCES}

Amougou, J.A., Tchindjang, M., Haman, U. and Batha, R.A.S., 2013. A comparative study of the influence of climatic elements on cocoa production in two agrosystems of bimodal rainfall: Case of Ngomedzap forest zone and the contact area of forestsavanna of Bokito. J. Cameroon Acad. Sci., 11: 27-37.

Barrett, C.B., Bezuneh, M. and Aboud, A. 2001. Income diversification, poverty traps and policy shocks in Cote d'Ivoire and Kenya. Food Policy, 18.

Caviglia-Harris, J.L. and Sills, E.O. 2005. Land use and income diversification: comparing traditional and colonist populations in the Brazilian Amazon. Agric. Econ., 32: 221-237.

Chuku, C.A. and Okoye, C. 2009. Increasing resilience and reducing vulnerability in sub- Saharan African agriculture: Strategies for risk coping and management. Afr. J. Agric. Res., 4: 12.

Dedieu, B., Servière, G., Madelrieux, S., Dobremez, L. and Cournut, S. 2006. Comment appréhender conjointement les changements techniques et les changements du travail en élevage? Cah. Agric., pp. 506-513.

Degrande, A., Schreckenberg, K., Mbosso, C., Anegbeh, P., Okafor, V. and Kanmegne, J. 2006. Farmers' Fruit Tree-growing Strategies in the Humid Forest Zone of Cameroon and Nigeria. Agrofor. Syst., 67: 159-175.

Dormady, N., Roa-Henriquez, A. and Rose, A. 2018. Economic resilience of the firm: A production theory approach. Int. J. Prod. Econ., 208: 446-460.

Dury, S. and Temple, L. 1999. La diversification fruitière des exploitations péri-urbaines dans la région de Yaoundé, quelles conséquences pour l'orientation de la recherche développement? No Cirad-00948368 6.

Jacobi, J., Mukhovi, S., Llanque, A., Toledo, D., Speranza, C.I., Käser, F., Augstburger, H., Delgado, J.M.F., Kiteme, B.P. and Rist, S. 2019. Actor-specific risk perceptions and strategies for resilience building in different food systems in Kenya and Bolivia. Reg. Environ. Change, 19: 879-892.
Jagoret, P., Michel-Dounias, I. and Malézieux, E. 2011. Longterm dynamics of cocoa agroforests: a case study in central Cameroon. Agrofor. Syst., 81: 267-278.

Jagoret, P., Ngogue, H.T., Bouambi, E., Battini, J.-L. and Nyassé, S. 2009. Diversification des exploitations agricoles à base de cacaoyer au Centre Cameroun : mythe ou réalité ? Biotechnol. Agron. Soc. Env., 10.

Kamdem, C.B. 2019. Libéralisation du marché et intégration du marché du cacao au Cameroun. Rev. Int. Econ. Lang. Francaise, 4: 118-141.

Lin, B.B, 2011. Resilience in Agriculture through Crop Diversification: Adaptive Management for Environmental Change. BioScience, 61: 183-193.

Mahob, R., Ndoumbe-Nkeng, M., Ten Hoopen, G., Dibog, L., Nyasse, S., Rutherford, M., Mbenoun, M., Babin, R., Amang A Mbang, J., Yede, Y. and Bilong Bilong, C. 2014. Pesticides use in cocoa sector in Cameroon: characterization of supply source, nature of actives ingredients, fashion and reasons for their utilization. Int. J. Biol. Chem. Sci., 8: 1976-1989.

Mertz, O., Wadley, R.L. and Christensen, A.E. 2005. Local land use strategies in a globalizing world: Subsistence farming, cash crops and income diversification. Agric. Syst., 85: 209-215.

Ndo, E.G.D. 2011. Évaluation des facteurs de risque épidémiologique de la phaeoramulariose des agrumes dans les zones humides du Cameroun (Thèse de doctorat). Montpellier-SupAgro, France.

Ndoumbe-Nkeng, M., Cilas, C., Nyemb, E., Nyasse, S., Bieysse, D., Flori, A. and Sache, I. 2004. Impact of removing diseased pods on cocoa black pod caused by Phytophthora megakarya and on cocoa production in Cameroon. Crop Prot., 23: 415-424.

Prosperi, P., Allen, T., Cogill, B., Padilla, M. and Peri, I. 2016. Towards metrics of sustainable food systems: a review of the resilience and vulnerability literature. Environ. Syst. Decis., 36: 3-19.

Roesch-McNally, G.E., Arbuckle, J.G. and Tyndall, J.C. 2018. Barriers to implementing climate resilient agricultural strategies: The case of crop diversification in the U.S. Corn Belt. Glob. Environ. Change, 48: 206-215.

Shi, Z., Watanabe, S., Ogawa, K. and Kubo, H. 2018. Reviews of resilience theories and mathematical generalization, in: Structural Resilience in Sewer Reconstruction. Elsevier, pp. 17-78.

Sonwa, D.J., Weise, S.F., Schroth, G., Janssens, M.J.J. and Howard-Yana Shapiro, 2014. Plant diversity management in cocoa agroforestry systems in West and Central Africa-effects of markets and household needs. Agrofor. Syst., 88: 1021-1034.

Tijani, A.A. 2006. Pesticide Use Practices and Safety Issues: The Case of Cocoa Farmers in Ondo State, Nigeria. J. Hum. Ecol., 19: 183-190. 
$\underset{\text { AESSRA }}{\sqrt{U}}$ Kaldjob et al.

Waha, K., van Wijk, M.T., Fritz, S., See, L., Thornton, P.K., Wichern, J. and Herrero, M. 2018. Agricultural diversification as an important strategy for achieving food security in Africa. Glob. Change Biol., 24: 3390-3400.
Youbi, E.M., Aléné, C.D., Fomena, A., Babin, R. with Tadu, Z., Djiéto-Lordon, C., Yede, 2014. Ant mosaics in cocoa agroforestry systems of Southern Cameroon: influence of shade on the occurrence and spatial distribution of dominant ants. Agrofor. Syst., 88: 1067-1079. 